Southern Methodist University

SMU Scholar

Faculty Journal Articles and Book Chapters

Faculty Scholarship

2009

\title{
A Brief Reflection on the Problem of Person-Altering Consequences
}

Gregory S. Crespi

Southern Methodist University, Dedman School of Law

\section{Recommended Citation}

Gregory S. Crespi, A Brief Reflection on the Problem of Person-Altering Consequences (2009)

This document is brought to you for free and open access by the Faculty Scholarship at SMU Scholar. It has been accepted for inclusion in Faculty Journal Articles and Book Chapters by an authorized administrator of SMU Scholar. For more information, please visit http://digitalrepository.smu.edu. 


\section{DEDMAN}

School of Law

A Brief Reflection on the Problem of

Person-Altering Consequences

Gregory Scott Crespi, Professor of Law

\section{SMU Dedman School of Law Legal Studies Research Paper Number 00-43}

This paper can be downloaded without charge from the Social Science Research Network electronic library at: http://ssrn.com/abstract $=1393839$ 
A Brief Reflection on the Problem
Of Person-Altering Consequences

by

Gregory Scott Crespi*

*Professor of Law, Dedman School of Law, Southern Methodist

University. J.D., Yale; Ph.D. University of Iowa.

Preliminary Draft

April 13, 2009 
Many social policies require substantial sacrifices by existing persons in order to benefit the members of distant future generations. Particularly salient examples of this are the elaborate and expensive efforts now undertaken to prevent high-level radioactive wastes from polluting the biosphere, or the stringent restrictions that may be soon be imposed on burning fossil fuels in order to mitigate the long-term climate change consequences of global warming. However, this trade-off does not only exist in the environmental policy area. Many other social policies also call for substantial sacrifices to be made at least partly if not largely on behalf of distant future generations.

The existence of this trade-off presents a fundamental and difficult ethical question that is far too often overlooked by policy makers. Do we have any ethical obligations at all to the yet-unborn members of future generations? Are we under a moral obligation to consider their interests, as best we can anticipate what those interests will be, as well as our own concerns in making these policy decisions? Or are we morally free to choose among policies solely with regard to their consequences for existing persons, with no obligations to concern ourselves with their impacts on future generations? In this brief essay I will try to demonstrate that this is a far more difficult question to answer than is commonly realized. 
If we do in fact have ethical obligations to take into account the impacts of our policies upon future generations, then this raises the derivative question of how then should we balance the interests of the members of those future generations with the rights and interests of existing persons? I will try to show that this is also a much tougher question to answer than is generally understood.

There is a fairly broad consensus among current policy makers that we do have ethical obligations to future generations to take their interests into account in choosing our actions. One rarely if ever hears arguments to the contrary. There is, of course, considerable controversy regarding the precise nature and scope of these obligations. But there does appear to be general agreement that we do have some such moral obligations that we need to respect. In addition, at least in America if not elsewhere, there is also a broad consensus that the primary analytical framework that should be used for measuring and balancing the legitimate interests of future generations against the interests of existing persons is a costbenefit analysis framework. ${ }^{1}$ In this framework the impacts of a policy on each affected generation are measured by the yardstick of the willingness-to-pay of its members to enjoy or to avoid the policy's consequences, and then those future impacts of the policy are 
appropriately discounted to a smaller present value, prior to their aggregation with its current impacts, in making an overall assessment of the merits of the policy. ${ }^{2}$

I have written several related articles over the past few years in which I have tried to broaden the conversations now taking place regarding these difficult ethical and policy assessment questions in the environmental policy context by arguing in some detail that they cannot be adequately addressed without also taking into account in some fashion what I have called "the problem of person-altering consequences." ${ }^{33}$ This important problem is unfortunately largely if not completely overlooked in current discussions. In this short essay I hope to generalize this analysis and communicate to a broader readership the nature of this problem, and make clear that the problem also comes up with regard to many other social policy decisions outside of the environmental context that also pose trade-offs between the impacts on existing persons and those affecting future generations. ${ }^{4}$

The central idea that I would like to communicate here is the simple yet momentous point that all social policies will inevitably have geometrically proliferating and eventually universal and eternal personaltering consequences. That fact has major implications for 
conceptualizing the nature of our ethical obligations to future generations, if there in fact are any such obligations, and for balancing the interests of future generations against those of existing persons when formulating policies.

Let me begin by briefly explaining exactly what I mean by the phrase "person-altering consequences," and then I will try to make clear the dramatic and rather troubling implications such consequences present for determining our ethical obligations to future generations, and for the assessment of policies. This phrase is one that I myself have coined, but the underlying concept is not original to me but derives from work done in the late-1970's and early-1980's by the noted British philosopher Derek Parfit and some of his academic contemporaries. ${ }^{5}$ Parfit originally, and in my opinion somewhat inaptly, labelled his insight the "Non-Identity Problem," ${ }^{\prime 6}$ and it has been later discussed by other philosophers under that moniker, but I have chosen to use what I think is the more descriptively accurate phrase "person-altering consequences" that better communicates its core meaning.

Parfit's insight is one of those simple yet profound insights that sometimes win people Nobel Prizes 30 or 40 years later after their significance becomes widely appreciated. It is an idea that is pretty 
obvious once it is explained to you. It then seems like something that you have already known all along, even if you have never fully articulated it to yourself or to anyone else, yet it is an insight with dramatic implications for many fields of law.

Parfit's insight starts with the recognition of the indisputable fact that the particular sperm-egg fusion that results from a successful act of human reproduction is an event that is radically contingent. The outcome is highly sensitive to minor changes in any of a large number of factors. Which particular one of the hundreds of millions of sperm that are released in an ejaculation will unite with the female egg, if any, is a very uncertain event. Even the slightest change in the timing or any other aspect of a reproductively successful act of intercourse will almost surely lead to a different sperm-egg fusion, and therefore ultimately to the birth of a genetically different individual than would have otherwise been born. The person now conceived and born will be a different individual in the most fundamental genetic sense.

The consequences of this simple fact are momentous. Any social policy measure that is significant enough in its direct or indirect impact on human behaviour to lead to even a single different sperm-egg fusion taking place will create a genetically different individual than the person 
that would have been born absent the implementation of the policy. Even the most minor and locally-focused policy will surely have that much impact on someone's behavior. And over time, as that now genetically different individual is born and matures and over their life influences numerous other people in major or minor ways, this will result in an exponentially spreading cascade of individuals being conceived and born that are now genetically different from those persons that would otherwise have been conceived and born absent the policy's initial impact. This cascade of genetic alterations will lead eventually (and probably sooner rather than later) to the creation of an entirely different population of human beings for all the rest of eternity than those persons that would have been conceived and born absent that initial and perhaps very minor policy impact.

In other words, even a quite small initial policy impact will ultimately lead, after a period of time probably on the order of no more than a few decades at the most, to the entire human population that would have been born and lived their lives throughout the rest of eternity from that point on now never even coming into existence. ${ }^{7}$ They will instead be replaced by a population consisting of genetically different individuals. Yet another way to put this is that any social policy will have rapidly spreading and eventually universal person-altering 
consequences in that it will alter the fundamental genetic identities of all future persons. Moreover, those person-altering consequences can be seen to be necessary conditions of the existence of all future persons who come into existence, since those persons would never have been conceived and born absent the policy's implementation. Those consequences make life possible for the members of future generations who are conceived and born, and will thus be far more significant to those persons than are all of the other impacts of the policy combined.

Most attempts to assess the ethical implications of policies that have long-term effects as well as immediate impacts, or to value in dollar terms the overall effects of such policies, have simply ignored these person-altering consequences. As a result, the conclusions that these efforts have reached are unfortunately irrelevant for assessing the relative merits of the actual choices that those policies present.

As an example, consider for a moment the seemingly rather radical approach of taking all of our existing high-level radioactive wastes, on which we now devote literally billions of dollars/year of resources to try to isolate from the biological environment, and simply putting those wastes into ordinary, inexpensive steel barrels with perhaps 150- to 200year containment capabilities in a salt-water environment, and then 
dumping them by barge somewhere into the middle of the Pacific Ocean and just forgetting about them. The likely response by current world leaders to such a proposal would be that this would be an outrageous violation of our ethical obligations to consider the welfare of distant future generations. Moreover, a typical cost-benefit analysis of this waste-dumping policy would doubtless conclude that it would result in such massive burdens for all distant future generations, commencing perhaps 200 years or so from now and continuing on for eons untold, that even when the benefits to existing persons of freeing those billions of dollars/year of resources for other uses are considered the policy's impacts would still be on balance massively negative. Such an ocean waste-dumping proposal would be a complete non-starter politically, I am sure.

The conventional framework of analysis that underlies this disparaging conclusion, however, implicitly involves an assessment of how future persons would likely feel about living in a world with a potentially very serious ocean radioactive waste problem, as compared to those same persons experiencing their lives without that radioactive waste problem. But this comparison is revealed to be totally inapt, and thus irrelevant to the real choices at hand, once one is aware of person-altering 
consequences. The proper comparison of alternatives that should be made for ethical and policy valuation purposes is quite different.

Let me explain. If we were to continue to spend billions of dollars/year on high-level radioactive waste storage, as we do now, there will then be one particular population of future persons conceived and born over time in future years. If, however, we cheaply dump those radioactive wastes into the Pacific Ocean in simple steel barrels, and free those billions of dollars/year of resources for other uses, those new uses of those considerable resources will immediately trigger an exponentially spreading cascade of person-altering consequences. Well before the time perhaps a couple of centuries from now or so when those radioactive toxins begin to leak into the biosphere, the entire human population alive then and later coming into being for the rest of eternity will owe their very existence to that waste-dumping policy; it will have been a necessary condition of their conception and birth. They would simply never have been conceived and born had the ocean radioactive wastedumping not taken place. In that event an entirely different group of persons would have come into being. 
The proper hypothetical question to imagine posing to those future persons who live in the post-ocean waste dumping world, for either ethical assessment or policy valuation purposes, is therefore:

"Do you prefer the world that you now live in, facing as you do a perhaps quite serious ocean pollution problem resulting from our prior radioactive waste-dumping policy, to a world which is without such a radioactive waste problem, but which is also a world in which neither you nor any of the people you have ever known have ever come into existence?"

In other words, the proper hypothetical question to ask is "Do you prefer living your life with the radioactive waste problem, or would you prefer non-existence?" That Hobson's Choice is in fact the true choice of alternatives that would be presented to them! My surmise, from what I know of people (and supported by the statistically rather low suicide rates) is that virtually everyone asked this question would strongly prefer their existence, even with the particular and perhaps serious set of problems that their life posed for them, to non-existence. If this is the case, then we have not actually harmed any person by dumping those radioactive wastes into the Pacific Ocean.

If we do dump those wastes into the ocean, then those future persons who are conceived and born with the radioactive waste problem to deal with, if they thought about it, would be grateful for what we have done, in a sense, because they would not otherwise exist. On the other 
hand, one can at least imagine the untold zillions of what one might loosely call "unrealised potential persons," that is, persons who might have been conceived and born under other circumstances, but who as a result of our choices will now never actually be conceived. But those wholly imaginary and non-existent unrealised potential persons of course have no standing to complain about the particular choices that we have made. My conclusion, admittedly troubling but seemingly impossible to avoid, is that since we probably will not harm any actual future person by our ocean radioactive waste-dumping actions, since they would likely all strongly approve of our actions so that they could come into existence, then under the conventional secular, consequentialist ethical premises that underlie most modern thinking ${ }^{8}$ we would simply not have violated any ethical obligations to anyone by dumping those radioactive wastes in the Pacific Ocean.

More broadly, and rather disturbingly, the pervasiveness of personaltering consequences means that any social policy that we undertake, no matter how radically present-oriented it is, and no matter how indifferent we are to its long-term consequences for future persons, is ethically selfvalidating under conventional ethical criteria in that one of its consequences will the person-altering consequence of bringing into being a future population that would not want us to have acted in any other 
way. So why not just dump those radioactive wastes into the Pacific Ocean and free lots of resources for the enjoyment of existing persons?

Where does this line of thinking lead, as a practical matter? Well, if one now recognizes the nature of the problem posed for conventional ethical assessment by person-altering consequences, but still feels at an intuitive level, as I do, that there must somehow be something morally wrong with pursuing such radically present-oriented policies as my ocean radioactive waste-dumping hypothetical, then I would like to suggest that what one is actually doing, probably implicitly rather than explicitly, is applying a non-consequentialist ethical criterion to condemn such policies. That is, one is likely applying an ethical criterion that is not grounded upon an assessment of the policy's consequences for the specific individual persons who will later come into being, but one that assesses the ethical merits of a policy on some basis other than those consequences. In addition, one is also, again probably implicitly rather than explicitly, applying some valuations algorithim in order to translate this non-consequentialist policy assessment into a rather large number in dollar terms before aggregating it with the conventional, financial measure of the policies' consequences for existing persons, in order to reach such an overall negative assessment of the merits of the policy. 
It is indeed a major step for one to leave the safe moorings of conventional secular, consequential ethical premises for the murky and uncharted waters of non-consequentialist ethical standards and policy valuation criteria. One is certainly free to reject the use of conventional ethical standards and proceed in this other fashion, if one chooses. But I would recommend that before one does so one first reflects carefully upon what alternative, non-consequentialist ethical premises they are explicitly or implicitly applying in making these assessments, and whether they really do accept those ethical premises as valid. In addition, I would recommend that one also try to be clear about the justifications for the particular valuation algorithim one is are using to quantify the non-consequentialist assessment of a policy in dollar terms before aggregating that assessment with the policy's consequences for existing persons to reach overall conclusions.

The problem of person-altering consequences not only dramatically undercuts conventional, secular ethical thinking, but also renders rather useless the widely-used framework of cost-benefit analysis ${ }^{9}$ that is based on the methodology of aggregating the willingness-to-pay of the persons affected by a policy to evaluate its merits. Let me briefly explain. 
Conventional cost-benefit analysis assesses the impacts of policies on future generations by hypothetically positing the willingness-to-pay question to the same hypothetical future persons under two different scenarios, life with the policy impacts and life without the policy impacts, and then comparing the answers to evaluate the policy. ${ }^{10}$ The assumption is therefore made, usually implicitly rather than explicitly, that the same future persons will exist whether or not a policy is implemented. This "same persons will exist either way" assumption is, however, clearly revealed to be untenable once one recognizes the existence of personaltering consequences. When conducting cost-benefit analyses, future persons' hypothetical willingness-to-pay valuations of a policy's impacts should instead be made as compared to the actual, demonstrable alternative of those persons' non-existence, should that policy not be implemented.

Unfortunately, if the hypothetical willingness-to-pay question was to be posed in this proper fashion that contrasts the actual achievable alternatives, any policy whatsoever would likely receive a massive (if not infinite) positive valuation from each of the specific future populations of individuals that the policy will bring into existence. ${ }^{11}$ Even if these valuations are then discounted quite heavily to reflect their futurity, one will still inevitably conclude that all policy alternatives whatsoever, 
including the null option of taking no action of any sort which would lead to the birth of a particular specific population of future individuals over time that would obviously favor that inaction, will generate massive future benefits. These massive future benefits extending for all eternity are obviously going to be impossible to meaningfully quantify and compare across alternatives, and in any event the size of those future benefits will completely dominate and render trivial any adverse policy impacts upon existing persons, no matter how widespread and severe those current impacts might be. ${ }^{12}$ This bizarre, blanket result that all policy options whatsoever will generate massive net benefits of indeterminate size that completely dominate any adverse impacts upon existing persons would render any cost-benefit analyses done in this fashion rather useless as a practical tool for helping policy makers to choose among policy alternatives.

One could perhaps attempt to try to salvage in part the cost-benefit framework of analysis by, again, instead first applying a nonconsequentialist ethical criterion to assess the significance of a policy for future generations, rather than using the normal secular, consequentialist willingness-to-pay framework, and then attempt to quantify into dollar terms in some fashion this non-consequentialist assessment before aggregating it with the usual willingness-to-pay based assessment of the 
policy's impacts on existing persons. ${ }^{13}$ But I will be the first to admit that I have no idea what would be the appropriate non-consequentialist ethical criterion to apply.

Consider again my ocean radioactive waste dumping hypothetical. What, exactly, is morally wrong with doing something like this that as I have shown will benefit virtually all if not all existing and future persons, by their own assessments? Has God somewhere decreed that radically present-oriented policies are morally wrong, even if no existing or future person is thereby injured? What evidence exists supporting this claim?

Alternatively, should we retain a secular orientation, but now focus upon the nature of the intentions of the actors, rather than upon the inevitably beneficial consequences of their actions for future generations given their person-altering consequences? But are intentions rather than likely results the proper ethical touchstone? Or should we perhaps take the tact of ascribing existential reality and moral significance to some impersonal, collective generalization such as, for example, "the human race," and then to try evaluate policies in terms of their beneficial or adverse impacts upon this collective generalization that stand apart from the policy's impacts upon the specific individuals that together comprise that generalization? But does the "human race" really exist apart from 
the specific individuals that comprise it, and even if it does exist in some sense do we really owe ethical obligations to anyone or anything except specific individuals? Finally, even if we can somehow come up with a plausible non-consequentialist ethical criterion for policy analysis, I have no idea of how one would then meaningfully translate such a nonconsequentialist assessment into dollar terms for aggregation with the policy's consequences for existing persons, in order to reach a meaningful overall policy assessment.

Let me briefly summarize my conclusions. Once one recognizes the nature and ubiquity of person-altering consequences, one is unfortunately forced to concede that all policy alternatives whatsoever are ethically self-validating if one judges them by conventional secular, consequentialist ethical standards. Those ethical criteria thus can no longer provide meaningful moral guidance as to when sacrifices by existing persons on behalf of distant future generations are called for, if ever. This presents a real conundrum for policy makers, since there is little if any consensus regarding which if any of the many competing secular or theistic non-consequentialist ethical criteria should be applied to assess future policy impacts in making decisions, nor how such nonconsequentialist assessments are to be quantified into dollar terms for aggregation with the policy consequences for existing persons. 
Moreover, cost-benefit analysis is now shown to be an untenable analytical approach, since cost-benefit analyses that ignore personaltering consequences are clearly irrelevant to the real choices at hand, and such analyses that incorporate person-altering consequences in the usual willingness-to-pay manner will always unhelpfully conclude that all policy options whatsoever will generate massive net benefits of uncertain magnitude that will completely dominate any adverse impacts upon existing persons.

So the person-altering consequences of policies indeed pose a significant intellectual problem, and one that I am admittedly at somewhat of a loss as to how to resolve. I hope that I have made clear, however, that the current practice of simply ignoring person-altering consequences is untenable, and that we need to figure out a better way to address those consequences.

\footnotetext{
1 “American government is becoming a cost-benefit state." Cass R. Sunstein, The Cost-Benefit State; The Future of Cost Benefit Regulatory Protection (2002), at 19-20.

${ }^{2}$ For a general discussion of cost-benefit analysis, and of the numerous criticisms that have been made of this approach, see generally Gregory Scott Crespi, "The Fatal Flaw of Cost-Benefit Analysis: The Problem of Person-Altering Consequences," 38 Env. L. Rep. 10703, 10703-06 (2008) (hereinafter "Crespi (2008)"), and the sources cited therein.

${ }^{3}$ Crespi, id.; Gregory Scott Crespi, "Would it be Unethical to Dump Radioactive Wastes in the Ocean? The Surprising Ethical Implications of the Problem of Person-Altering Consequences," 1 Ecol. L. Cur. 1 (2008); Gregory Scott Crespi, "What's Wrong With Dumping Radioactive Wastes in the Ocean? The Surprising Ethical and Policy Analysis Implications of the Problem of Person-Altering Consequences," 37 Env. L. Rep. 10873 (2007) (hereinafter “Crespi (2007)”).
} 


\footnotetext{
${ }^{4}$ This short essay is intended only to communicate the essential nature of the problem of personaltering consequences. For more detailed discussion of the numerous technical issues raised by personaltering consequences for ethical assessment and for cost-benefit analysis see generally id.

${ }^{5}$ See Crespi (2007), supra n. 3, at 10876-79 and the sources cited therein.

${ }_{7}^{6}$ Id. at 10876.

${ }^{7}$ I have discussed elsewhere in some detail the issues presented by those "transitional" generations of persons conceived and born after the person-altering consequences of a policy have begun to spread but before they become universal. See Crespi (2007), supra n. 3, at 10885.

${ }^{8}$ By the phrase "secular premises" I refer to ethical premises that are derived from reflections on the human condition that are agnostic with regard to the question of the existence of a supreme supernatural being. By the phrase "consequentialist premises" I refer to the ethical premise that actions have ethical relevance only to the extent that they have consequences for the rights or interests of specific persons.

${ }^{9}$ Sunstein, supra $\mathrm{n} .1$.

${ }^{10}$ Crespi (2008), supra n. 2, at 10705.

${ }^{11}$ If the willingness-to-pay of those future persons were to be measured by their offer prices, the aggregate benefit measure would be very large but finite because of wealth constraints on offer prices. If, however, asking prices were used as the measure, those benefits would obviously be infinite. Id. at 10709-10. Whether offer prices or instead asking prices are the appropriate measure of willingness to pay is a difficult and unresolved question. For an extended discussion of this point, see generally Gregory Scott Crespi, "Valuation in Cost-Benefit Anlysis: Choosing Between Offer Prices and Asking Prices as the Appropriate Measure of Willingness to Pay," 39 J. Mar. L. Rev. 429 (2006).

${ }^{12}$ Crespi (2008), supra n. 2, at 10711.

${ }^{13}$ Id. at $10715-16$.
} 